\title{
Electromagnetic Radiations on the Functional Potential of Spermatozoa
}

Dhasarathan P, Elizabeth Mathew MG, Athinarayanan AJ and Ranjitsingh $\mathbf{A}^{*}$

Department of Biotechnology, Prathyusha Engineering College, Chennai-602025, India

*Corresponding author: Ranjitsingh A, Department of Biotechnology, Prathyusha Engineering College, Chennai-602025, India

Received: May 20, 2021; Accepted: June 09, 2021; Published: J une 16, 2021

\begin{abstract}
The growing exposure to digital communication system and tools leads to radiation toxicity to the users. Unaware of the safety measures even a kid at the age of one starts operating digital gadgets emitting Radio frequencyelectromagnetic radiations. Radiations from mobile phones laptops, note pad, Wi-Fi or other devices are reported to be harmful beyond the permissible limit. So there is a growing concern for the overall health, reproductive, and hormonal functions. Experimental studies were conducted by using a Wi-Fi network active laptop and live spermatozoa. The exposure of sperms to the source of EMF showed that the activity of the live sperms got reduced and mortality was observed depending on the exposure duration and the distance from EMF sources. After $5 \mathrm{~h}$ of exposure to RF-EMF source the semen quality changed when compared with control. The vitality of sperm in the control was $95 \pm 1.0$ after $2 \mathrm{hr}$ and it was reduced to $60 \pm 1.5$ percent at a distance of $1 \mathrm{~cm}$ and $55 \pm 2.2$ percent at a distance of $10 \mathrm{~cm}$. After 5 hour exposure, the vitality was reduced to $63 \pm 1.86$ at $1 \mathrm{~cm}$ distance and $70 \pm 1.42$ at $10 \mathrm{~cm}$ distance. The reduction in vitality of sperm after exposure to RF-EMF source for 2 hour was $35 \%$ at $1 \mathrm{~cm}$ and $40 \%$ at $10 \mathrm{~cm}$ distance.
\end{abstract}

Keywords: RF-EMF; Digital devices; Mobile phone; Sperms; Laptop; Wi-Fi

\section{Introduction}

In this era of digitalization, most of people are exposed to electromagnetic radiations emitted from electronic devices. The rise in the use of mobile phones, laptops, wireless internet, access through Wi-Fi routers and modem in COVID-19 pandemic period may leave harmful effects on the fertility parameters. Exposure to Electromagnetic Radiation (EMR) from mobile phones was reported to affect human spermatozoa [1]. EMR induces scrotal hyperthermia and oxidative stress leading to the dysfunction of the sperms and infertility [1,2]. Electromagnetic pollution due to cell phone towers had induced deleterious changes in the human biochemical process and alterations in blood glutathione $S$ transferase and total antioxidant activity in Jordanian people [3]. Electromagnetic radiations interfere with mitochondrial electron transport chain in spermatozoa and affect the sperm function as reported earlier workers [4-9]. The electromagnetic radiations caused oxidative stress in sperm functioning [10-12]. Exposure of male rats to radiation emitted from Wi-Fi device had increased the serum 8-hydroxy -2 deoxyguanosine levels followed by DNA damage in germ cells [13]. Maternal The use of cell-phone during pregnancy reflected in shorter pregnancy duration and preterm birth, [14]. The pregnant mother using mobile phone cell phone use for a long duration had increased the offspring behavioral problems, particularly hyperactivity/inattention [15].

The Radio Frequency and Electromagnetic Field (RF-EMF) at a level of $850 \mathrm{MHz}-2.4 \mathrm{GHz}$ gets absorbed by the human body [16] RF-EMF exposure leads to breast cancer [17]. RF-EMF increases superoxide anions concentrations in the germ cells of males leading to oxidative stress and decrease in sperm motility [18]. Prolonged use of laptop computers decreased the sperm vitality and count [19]. Wi-
Fi radiation induced adverse effect on male reproductive system is extensively reviewed $[20,21]$.

As there are several reports on the impact of $\mathrm{Wi}$-Fi radiations on sperm quality, the present study is planned to analyze the impact of radiations from laptop on live perm incubated at different distance and duration.

\section{Material and Methods}

\section{Incubation of spermatozoa near laptop connected to net setter}

The present study was done on Twenty five normozoospermic semen donor samples cryopreserved in a fertility clinic in South India was used. The sperm concentration was adjusted to 15 million $/ \mathrm{ml}$. Each prepared sperm suspension sample was aliquoted in 3 fractions and a drop of $500 \mathrm{ml}$ was placed in $35 \times 10 \mathrm{~mm}$ Petri dishes [22]. This was covered with $3 \mathrm{ml}$ of ovoil (Vitrolife) to avoid evaporation. Fractions one were incubated near active laptop connected to net setter. Another factions (control group) were incubated under similar conditions without the laptop. To induce the greatest possible effect, the laptop worked actively (uploading and downloading information) throughout the period of exposure. The distance between the computer and each fraction was kept constant at $1 \mathrm{~cm}$ and $10 \mathrm{~cm}$. The duration of exposure was 2 hours and 5 hours. The temperature near the laptop was kept at $26^{\circ} \mathrm{C}$ during the incubation time by an air conditioning system. The temperature on each medium drop was thoroughly controlled by a thermometer and recorded every 5 minutes. Unexposed aliquots were used as control and kept under identical temperature and conditions in another room away from any computers or electronic devices. After the incubation period, sperm vitality, motility, oxidative stress and DNA fragmentation were 
determined on each aliquot.

\section{Sperm vitality}

The semen samples were mixed well. From this mixture a $50 \mu \mathrm{l}$ aliquot of semen was taken out and mixed with an equal volume of eosin-nigrosin suspension. For each suspension smear was made on a glass slide and allowed it to dry in air. The slides were examined immediately after drying, or later after mounting with a permanent non-aqueous mounting medium. The slides were examined with bright field optics at $\times 1000$ magnification and oil immersion. The number of stained (dead) or unstained (vital) cells was tallied with the aid of a laboratory counter. Two hundred spermatozoa were evaluated in each replicate, in order to achieve an acceptably low sampling error.

\section{Scoring}

The nigrosin provides a dark background that makes it easier to discern faintly stained spermatozoa with bright field optics; live spermatozoa have white heads and dead spermatozoa have heads that are stained red or dark pink. Spermatozoa with a faint pink head were assessed as alive. If the stain is limited to only a part of the neck region, and the rest of the head area is unstained, this is considered a "leaky neck membrane", not a sign of cell death and total membrane disintegration. These cells were assessed as alive.

$$
\text { Vitality }(\%)=\frac{\text { Number of viable sperm }}{\text { Total number of } \text { sperm }} \times 100
$$

\section{Sperm motility studies}

The semen sample exposed to the radiations from laptop was used for further assay. Sperm motility within semen was assessed at a stabilized temperature, $37^{\circ} \mathrm{C}$, turn the stage warmer on 10 minutes in advance, to allow the temperature to stabilize. The sperm sample was taken in a sperm motility counter slides with a chamber of depth $20.7 \mu \mathrm{m}$. $6.5 \mu \mathrm{l}$ semen sample was taken in the chamber covered with an $18 \times 18 \mathrm{~mm}$ cover slip. The slide was examined with phasecontrast optics at $\times 200$ or $\times 400$ magnification. Then looked for spermatozoa in an area at least $5 \mathrm{~mm}$ from the edge of the cover slip to prevent observation of effects of drying on motility. The slide was systematically scanned to avoid repeatedly viewing the same area. The observation fields were changed often. The fields on the basis of the number of motile sperm seen were avoided (field choice was random). Scoring in a given field was at a random instant. Before the spermatozoa to swim into the field or grid, scoring was done. The motility of all spermatozoa within a defined area of the field was assessed. To avoid overestimating the number of motile spermatozoa scanning and count were done quickly. Initially the grid section was scanned for scoring Progressive Sperm (PR), next Nonprogressive (NP) spermatozoa were counted These three categories of sperm movement were scored at one time, and in larger areas of the grid. The number of spermatozoa in each motility category was tallied with the aid of a laboratory counter. About 200 spermatozoa in a total of at least five fields in each replicate where evaluated in order to avoid sampling error. The average percentage and difference between the two percentages for the most frequent motility grade (PR, NP) in the replicate wet preparations was calculated. Only intact spermatozoa (defined as having a head and a tail) are counted for sperm concentration assessment. Motile pinheads were counted. If no spermatozoa are observed in the replicate wet preparations, azoospermia was suspected.

$$
\begin{gathered}
\text { Progressive }(P R)(\%)=\frac{\text { Number of progressive sperm }}{\text { Total number of motile sperm }} \times 100 \\
\text { Non Progressive }(N P)(\%)=\frac{\text { Number of non }- \text { progressive sperm }}{\text { Total number of motile sperm }} \times 100 \\
\text { Detection of DNA Fragmentation }
\end{gathered}
$$

Prepared semen sample using density gradient centrifugation the resulting pellet was resuspeneded in $0.5 \mathrm{ml}$ of sperm wash media as in the washing step. Sperm DNA fragmentation was analysed with halo sperm (Halotech). The SDF was determined from chromatin depression patterns using the halo sperm kit (Halotech DNA), a commercial variant of the Sperm Chromatin Depression (SCD) test. For each experiment, $25 \mu \mathrm{l}$ of diluted spermatozoa $\left(10 \times 10^{6}\right.$ spermatozoa per $\mathrm{ml}$ ) was added to a vial containing low melting point agarose and gently mix. A small aliquot of the agarose - sperm mixture $(10 \mu \mathrm{l})$ was then spread on pre-treated slide (provided in the kit), covered with a glass cover slip and placed in a refrigerator on a cold metallic plate for 5 minutes. After solidification, a first step including a controlled denaturation of DNA using an acid solution for 7 minutes at room temperature was performed. Once the DNA was denatured in the putative DNA breaks, a controlled extraction of the nuclear proteins was produced. The DNA halos from the SCD test can be detected by Diff-Quick reagent. The degree of DNA dispersion was assessed by observing the relative halo size under bright field microscopy. A minimum of 500 spermatozoa per sample was evaluated. Sperm with large and medium sized halos are considered to be normal or non-fragmented sperm with small sized halo or no halo are considered to have significant DNA fragmentation. The percentages of DNA fragmentation assessed by calculating DNA Fragmentation Index (DFI). It was monitored by fluorescence and bright field microscopy, respectively.

$$
\begin{aligned}
& \text { DFI (DNA fragmentation Index })=\frac{\text { Fragmented DNA }}{\text { Fragmented DNA + Non Fragmented DNA }} \\
& \text { Sperm DNA fragmentation Index SDF }(\%)=\frac{\text { Number of spermatozoa with fragmented DNA }}{\text { No of spermatozoa counted }} \times 100
\end{aligned}
$$

\section{Reactive Oxygen Species Estimation}

Reactive Oxygen Species (ROs) released in the sperm sample exposed to RF-EMF source was estimated using chemiluminescence assay using luminol. Luminol gets oxidized in the presence of ROs. The luminescence generated by luminol was measured using luminometer (Luminometer, Vitl Life Science solutions). For the assay luminol (5-amino, -2,3- dihydro 1,4- phthalazinedione, Sigma-Aldrich) was prepared at a concentration $100 \mathrm{mmol} / \mathrm{L} / \mathrm{L}$ using DMSO (Dimethyl sulfoxide) and stored properly. From the stock solution $5 \mathrm{mmol} / \mathrm{L}$ luminol was prepared freshly before the experiment. For measuring chemiluminescence the semen samples exposed to radiations from laptop was liquefied gently using plastic pipette, and transferred to microfuge tube. To the semen sample ten microliters of luminol was added and mixed well before loading in to luminometer. The assay was done in a chamber with reduced light exposure. Every one minute after the addition of luminol into semen sample, chemiluminescence was noted as Relative Light Units/ (RLU/Sec $/ 10^{6}$ sperm) for 10 minutes. For negative control Phosphate Buffered Saline (PBS) was used. The positive control was prepared using $395 \mu \mathrm{l} \mathrm{PBS}$ and $5 \mu \mathrm{l}$ of 30 percent hydrogen peroxide $\left(\mathrm{H}_{2} \mathrm{O}_{2} \mathrm{O}\right)$ mixed with $10 \mu \mathrm{l}$ of $5 \mathrm{mM}$ luminol. The ROS value less than $24 \mathrm{RLU} /$ 
Table 1: Impact of RF-EMF exposure duration and distance on the semen characteristics.

\begin{tabular}{|c|c|c|c|c|c|c|}
\hline $\begin{array}{c}\text { Exposure duration } \\
(\mathbf{H r})\end{array}$ & $\begin{array}{c}\text { Distance } \\
(\mathbf{c m})\end{array}$ & \multicolumn{2}{|c|}{ Motility (\%) } & $\begin{array}{c}\text { DNA } \\
\text { fragmentation }\end{array}$ & $\begin{array}{c}\text { Vitality } \\
\text { ROs in term of chemiluminescence RLU/ } \\
\text { Sec/10 }\end{array}$ \\
\hline \multirow{2}{*}{2} & 1 & $53.0 \pm 1.5(35.0)$ & $31.0 \pm 0.25(-2.5)$ & $16.0 \pm 0.38(-10.7)$ & $60.0 \pm 1.5(35.0)$ & $985 \pm 15.0$ \\
\cline { 2 - 7 } & 10 & $55.0 \pm 1.0(33.0)$ & $29.0 \pm 1.0(10.5)$ & $10.8 \pm 1.0(-5.5)$ & $55.0 \pm 1.0(40.0)$ & $841 \pm 14.0$ \\
\hline \multirow{2}{*}{5} & 1 & $45.0 \pm 0.7(43.0)$ & $24.0 \pm 1.5(-5.5)$ & $16.7 \pm 0.85(-11.4)$ & $63.0 \pm 1.70(32.0)$ & $1216 \pm 23$ \\
\cline { 2 - 7 } & 10 & $48.0 \pm 0.90(40.0)$ & $26.0 \pm 1.0(-7.5)$ & $15.5 \pm 0.25(-10.2)$ & $70 \pm 1.40(25.0)$ & $926 . \pm 17$ \\
\hline
\end{tabular}

Sec $/ 10^{6}$ sperm is normal representing $87.2 \%$ of the ROS values of normal sperm parameters.

\section{Statistics}

The impact of RF-EMF on motility, vitality, DNA fragmentation and ROS level were statistically analysed with a significant test $\mathrm{P}<0.05$.

\section{Results}

In the present study the impact of RF-EMF emanated from a laptop connected to a Wi-Fi and working for 2-5 hours upon the male gametes, spermatozoa was analysed. To assess the quality of the sperms, the sperm vitality rate, progressive motility, non-progressive motility, DNA fragmentation index and ROS production in the semen samples were analysed by exposing the sperm sample to a laptop connected to a net setter at a distance of $1 \mathrm{~cm}$ and $10 \mathrm{~cm}$ for a period of 2-5 $\mathrm{h}$ without disturbing. The semen sample kept at a distance of $1 \mathrm{~cm}$ showed a reduction in sperm vitality and progressive motility when compared with control group. Also the DNA fragmentation index (DFI) and ROS level in sperm were estimated after 2 and $5 \mathrm{~h}$ of exposure. The deterioration of sperm quality (Table 1 and Figure 1) varied according to the exposure duration. After $5 \mathrm{~h}$ of exposure to RF-EMF source, the semen quality changed when compared with control. The vitality of sperm in the control was $95 \pm 1.0$ after $2 \mathrm{~h}$ and it was reduced to $60 \pm 1.5$ at a distance of $1 \mathrm{~cm}$ and $55 \pm 2.2$ percent at a distance of $10 \mathrm{~cm}$. After 5 hour exposure, the vitality was reduced to $63 \pm 1.86$ at $1 \mathrm{~cm}$ distance and $70 \pm 1.42$ at $5 \mathrm{~cm}$ distance. The reduction in vitality of sperm after exposure to RF-EMF source for 2 hour was $35 \%$ at $1 \mathrm{~cm}$ and $40 \%$ at $10 \mathrm{~cm}$ distance. After 5 hour exposure the reduction in vitality when compared to control was $32 \%$ and $25 \%$ respectively at 1 and $10 \mathrm{~cm}$ distance.

\section{Discussion}

The oxidative damages and accumulation of reactive oxygen species are reported to interfere with the vitality of the sperms as reported [5]. In conformity with the damage to vitality the RF-EMF radiations affected the motility of the sperm. The progressive motility of the sperm at 1 and $10 \mathrm{~cm}$ distance was significantly reduced after exposure to RF-EMF radiations from computer. The decrease in progressive motility was also correlated with exposure durations. When compared with control the reduction in sperm motility (PS) was $35 \%, 30 \%, 45 \%$ and $40 \%$ respectively at $1 \mathrm{~cm}, 10 \mathrm{~cm}$ distance after $2 \mathrm{~h}$ and $5 \mathrm{~h}$.

The non-progressive motile sperm in the control group was $18.5 \pm 0.41 \%$. The percentage of non- progressive motile sperm got significantly elevated $(31.0 \pm 1.5)$ at $1 \mathrm{~cm}$ distance after 2 hours and $26.0 \pm 1.20$ percent after $5 \mathrm{~h}$ duration. The percentage increase in non- motile sperm at $10 \mathrm{~cm}$ distance after $2 \mathrm{~h}$ and $5 \mathrm{~h}$ exposure

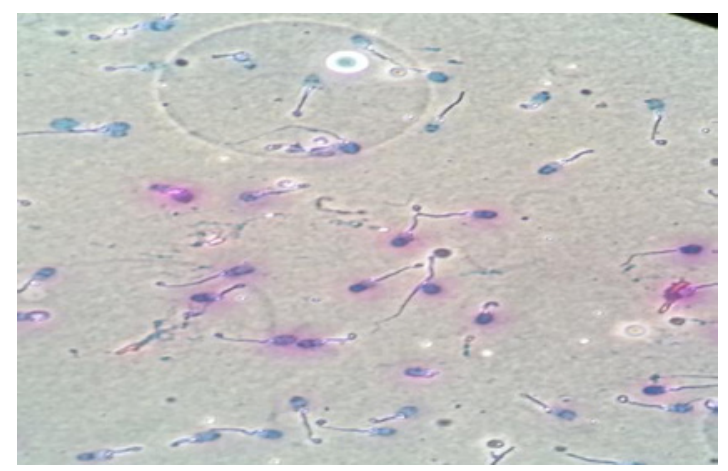

Figure 1: DNA fragmentation, abnormal sperm seen after exposure to EMF radiations.

duration were $10.5 \%$ and $7.5 \%$ respectively. The motility of the sperm is significantly affected due to the impact of RF-EMF radiations in different exposure duration and distance.

The integrity of the DNA inside the sperm cell decides the functional mechanism of sperms. There are several reports on RFEMF and oxidative stress and DNA damage spermatozoa (23).DNA fragmentation index in the control sample was $5.3 \pm 0.41$. In RF-EMF exposed sample for 2 hours at a distance of $1 \mathrm{~cm}$ and $1 \mathrm{~cm}$ the DFI were $16.0 \pm 0.38$ and $10.8 \pm 1.0$. After 5 hour exposure the DFI were $16.7 \pm 0.86$ and $15.5 \pm 0.25$ at $1 \mathrm{~cm}$ and $10 \mathrm{~cm}$ respectively.

It is well documented that the RF-EMF radiations from digital devices like mobile phones, laptop and Wi-Fi affect the sperm motality and progressiveness.Radiations from cell phone are found affecting sperm motility causing DNA fragmentation and alteration in gene expression [24-26]. Electromagnetic radiations from smart phone (1800 -MHZ) and Wi Fi (2.45 GHZ) made an imbalance in antioxidants in semen and damaged sperm DNA [27]. RFEMF exposure induces increased Reactive Oxygen Species (ROS) production from the mitochondria leading to deleterious effect on sperms $[6,28]$.

In the present study also the exposure of spermatozoa to the RFEMF from laptop with Wi -Fi functions affected its vitality, mobility and DNA integrity as reported [29]. In the present observation motility was less reduced in the semen sample kept at $10 \mathrm{~cm}$ when compared with $1 \mathrm{~cm}$ distantly located sperm sample. In the $5 \mathrm{~h}$ exposed sperm samples the impact of RF-EMF was high and the progressive motility, non-progressive motility and DFI were highly changed when compared with the sperm sample exposed to RF-EMF for $5 \mathrm{~h}$. It is reported that the RF-EMF emission from digital devices affect the reproductive physiology in the testes, and the functional characteristics of sperm [30]. The radiation induces micronuclei 
formation, changes in protein kinases, anti oxidative enzymes and disrupts genomic stability [31]. Radio Frequency Radiation (RFR) is reported to damage DNA and arrest cell cycle in the germ cells of male rats [32]. The radiations from cell phone affected the semen quality and fertility in males [33]. The exposure to radio frequency leads to proteotoxicity and cancer [34-36].

\section{Reactive Oxygen Generation}

Reactive Oxygen Species (ROS), is a free radical generated in oxygen metabolism influencing positive or negative function in nearest stable biomolecules. The excessive generation of ROS leads to an imbalance in antioxidant potential and ends in oxidative stress. The oxidative stress in normal spermatozoa causes damages and dysfunction. The optimum level of ROS production by spermatozoa is beneficial. But excessive generation of ROS causes deleterious effects on the structure and function of spermatozoa and also changes in blood parameters [3]. This is because of the fact that the Poly Unsaturated Fatty Acids (PUFA) present in the plasma membrane of spermatozoa undergo lipid peroxidation due to ROS attack. As a result the plasma membrane loses its integrity [37] and DNA damage occurs [38]. The electromagnetic radiation from mobile phones and $\mathrm{Wi}-\mathrm{Fi}$ devices increased oxidative stress in uterus and made degenerative changes in endocrine functions including a reduction in plasma prolactin, progesterone, and estrogen levels in pregnant rats [39].

\section{Conclusion}

The present study on the impact of radiations from a laptop upon the functional mechanism of spermatozoa confirmed that the operating the digital devices without precautionary measures and distance interferes with fertilizable ability of the sperms that may end in infertile marriage. The present users of laptop or other digital devices must think about the possible fertility problem from such devices if they are used continuously for a long time and at close proximity.

\section{References}

1. Okechukwu CE. Does the use of mobile phone affect male fertility? A minireview. J Hum Reprod Sci. 2020; 13: 174-183.

2. Gorpinchenko I, Nikitin O, Banyra O, Shulyak A. The influence of direct mobile phone radiation on sperm quality. Cent European J Urol. 2014; 67: 65-71.

3. Akkam Y, Al-Taani A, Ayasreh S, Almutairi A, Akkam N. Correlation of Blood Oxidative Stress Parameters to Indoor Radiofrequency Radiation: A Cross Sectional Study in Jordan. Int J Environ Res Public Health. 2020; 17: 4673.

4. Houston BJ, Nixon B, King BV, De luliis GN, Aitken RJ. The effects of radiofrequency electromagnetic radiation on sperm function. Reproduction. 2016; 152: R263-R276

5. Houston BJ, Nixon B, McEwan KE, Martin JH, King BV, Aitken RJ, et al Whole-body exposures to radiofrequency-electromagnetic energy can cause DNA damage in mouse spermatozoa via an oxidative mechanism. Sci Rep. 2019; 9: 17478.

6. Houston Brendan J, Brett N, King Bruce V, John AR, De Iuliis Geoffry N Probing the Origins of $1,800 \mathrm{MHz}$ Radio Frequency Electromagnetic Radiation Induced Damage in Mouse Immortalized Germ Cells and Spermatozoa in vitro Frontiers in Public Health. 2016; 6: 270.

7. Agarwal A, Deepinder F, Sharma RK, Ranga G, Li J. Effect of cell phone usage on semen analysis in men attending infertility clinic: an observational study. Fertil Steril. 2008; 89: 124-128.

8. Darbandi M, Darbandi S, Agarwal A, Henkle R, Sadeghi MR. The effects of exposure to low frequency electromagnetic fields on male fertility. Altern Ther Health Med. 2018; 24: 24-29.

9. Yu G, Tang Z, Chen H, Chen Z, Wang L, Cao H, et al. Long-term exposure to $4 \mathrm{G}$ smartphone radiofrequency electromagnetic radiation diminished male reproductive potential by directly disrupting Spock3-MMP2-BTB axis in the testes of adult rats. Sci Total Environ. 2020; 698: 133860

10. Górski R, Kotwicka M, Skibińska I, Jendraszak M, Wosiński S. Effect of lowfrequency electric field screening on motility of human sperm. Ann Agric Environ Med. 2020

11. Gautam R, Singh KV, Nirala J, Murmu NN, Meena R, Rajamani P. Oxidative stress-mediated alterations on sperm parameters in male Wistar rats exposed to $3 G$ mobile phone radiation. Andrologia 2019; 51: e13201.

12. Oh JJ, Byun SS, Lee SE, Choe G, Hong SK. Effect of electromagnetic waves from mobile phones on spermatogenesis in the Era of 4G-LTE. Biomed Res Int. 2018; 2018: 1801798.

13. Pall ML. Wi-Fi is an important threat to human health. Environmental Research. 2018; 164: 405-416.

14. Tsarna E, Reedijk M, Birks LE, Guxens M, Ballester F, Ha M, et al. Associations of Maternal Cell-Phone Use During Pregnancy With Pregnancy Duration and Fetal Growth in 4 Birth Cohorts. Am J Epidemiol. 2019; 188: 1270-1280.

15. Sudan M, Birks LE, Aurrekoetxea JJ, Ferrero A, Gallastegi M, Guxens M, et al. Maternal cell phone use during pregnancy and child cognition at age 5 years in 3 birth cohorts. Environ Int. 2018; 120: 155-162.

16. Agarwal A, Singh A, Hamada A, Kesari K. Cell phones and male infertility: A review of recent innovations in technology and consequences. Int Braz J Urol. 2011; 37: 432-454.

17. Shih YW, O'Brien AP, Hung CS, Chen KH, Hou WH, Tsai HT. Exposure to radiofrequency radiation increases the risk of breast cancer: A systematic review and meta-analysis. Exp Ther Med. 2021; 21: 23.

18. Rahban R, Nef S. Regional difference in semen quality of young men: a review on the implication of environmental and lifestyle factors during fetal life and adulthood. Basic Clin. Androl. 2020; 30: 16.

19. Avendaño C, Mata A, Sanchez Sarmiento CA, Doncel GF. Use of laptop computers connected to internet through Wi-Fi decreases human sperm motility and increases sperm DNA fragmentation. Fertil Steril. 2012; 97: 3945.e2.

20. Singh R, Nath R, Mathur AK, Sharma RS. Effect of radiofrequency radiation on reproductive health. Indian J Med Res. 2018; 148: 92-9.

21. Jaffar FHF, Osman K, Ismail NH, Chin KY, Ibrahim SF. Adverse Effects of Wi-Fi Radiation on Male Reproductive System: A Systematic Review. Tohoku J Exp Med. 2019; 248: 169-179.

22. Fácio CL, Previato LF, Machado-Paula LA, Matheus PC, Araújo E Filho. Comparison of two sperm processing techniques for low complexity assisted fertilization: sperm washing followed by swim-up and discontinuous density gradient centrifugation. JBRA Assist Reprod. 2016; 20: 206-211.

23. Suresh CMC, Kelly SA, Ashok A. Clinical relevance of oxidative stress and sperm chromatin damage in male infertility: an evidence based analysis. International braz j urol. 2007; 33: 603-621.

24. Sârbu A, Miclăus S, Digulescu A, Bechet P. Comparative Analysis of User Exposure to the Electromagnetic Radiation Emitted by the Fourth and Fifth Generations of Wi-Fi Communication Devices. Int $\mathrm{J}$ Environ Res Public Health. 2020; 17: 8837.

25. Li DY, Song JD, Liang ZY, Oskouei K, Xiao XQ, Hou WZ, et al. Apoptotic Effect of $1800 \mathrm{MHz}$ Electromagnetic Radiation on NIH/3T3 Cells. Int J Environ Res Public Health. 2020; 17: 819

26. Zalata A, El-Samanoudy AZ, Shaalan D, El-Baiomy Y, Mostafa T. In vitro effect of cell phone radiation on motility, DNA fragmentation and clusterin gene expression in human sperm. Int J Fertil Steril. 2015; 9: 129-136.

27. Ding SS, Sun $P$, Tian $H$, Huo $Y W$, Wang LR, Han $Y$, et al. Association between daily exposure to electromagnetic radiation from $4 \mathrm{G}$ smartphone 
and $2.45-\mathrm{GHz}$ wi-fi and oxidative damage to semen of males attending a genetics clinic: a primary study. Int J Clin Exp Med. 2018; 11: 2821-2830.

28. Delavarifar S, et al. "Low-power Density Radiations Emitted from Common Wi-Fi Routers Influence Sperm Concentration and Sperm Histomorphometric Parameters: A New Horizon on Male Infertility Treatment." Journal of biomedical physics \& engineering. 2020; 10: 167-176.

29. Aitken RJ, Bennetts LE, Sawyer D, Wiklendt AM, King BV. Impact of radio frequency electromagnetic radiation on DNA integrity in the male germline. Int J Androl. 2005; 28: 171-179.

30. Zha XD, Wang WW, Xu S, Shang XJ. [Impacts of electromagnetic radiation from cellphones and Wi-Fi on spermatogenesis]. Zhonghua Nan Ke Xue. 2019; 25: 451-455.

31. Kesari KK, Agarwal A, Henkel R. Radiations and male fertility. Reprod Biol Endocrinol. 2018; 16: 118.

32. Pandey N, Giri S, Upadhaya P. Radiofrequency radiation ( $900 \mathrm{MHz}$ )-induced DNA damage and cell cycle arrest in testicular germ cells in swiss albino mice. Toxicol Ind Health. 2017; 33: 373-384.

33. Al-Bayyari N. The effect of cell phone usage on semen quality and fertility among Jordanian males. Middle East Fertil Society J. 2017; 22: 178-182.

34. Poque E, Ruigrok HJ, Arnaud-Cormos D, Habauzit D, Chappe Y, Martin C, et al. Effects of radiofrequency field exposure on proteotoxic-induced and heatinduced HSF1 response in live cells using the bioluminescence resonance energy transfer technique. Cell Stress Chaperones. 2021; 26: 241-251.
35. Poque E, Arnaud-Cormos D, Patrignoni L, Ruigrok HJ, Poulletier De Gannes $F$, Hurtier A, et al. Effects of radiofrequency fields on RAS and ERK kinases activity in live cells using the bioluminescence resonance energy transfer technique. Int J Radiat Biol. 2020; 96: 836-843.

36. Hardell L, Carlberg M. Comments on the US National Toxicology Program technical reports on toxicology and carcinogenesis study in rats exposed to whole-body radiofrequency radiation at $900 \mathrm{MHz}$ and in mice exposed to whole-body radiofrequency radiation at 1,900 $\mathrm{MHz}$. Int J Oncol. 2019; 54 : 111-127.

37. Maneesh M, Jayalekshmi H. Role of reactive oxygen species and antioxidants on pathophysiology of male reproduction. Indian J Clin Biochem. 2006; 21 : 80-89.

38. Ollero M, Gil-Guzman E, Lopez MC, Sharma RK, Agarwal A, Larson K, et al. Characterization of subsets of human spermatozoa at different stages of maturation: implications in the diagnosis and treatment of male infertility. Hum Reprod. 2001; 16: 1912-1921.

39. Yüksel M, Nazıroğlu M, Özkaya MO. Long-term exposure to electromagnetic radiation from mobile phones and Wi-Fi devices decreases plasma prolactin, progesterone, and estrogen levels but increases uterine oxidative stress in pregnant rats and their offspring. Endocrine. 2016; 52: 352-362. 